\title{
UPRAVLJANJE KVALITETOM ZAVARENIH KONSTRUKCIJA POMOĆU INFORMACIONIH TEHNOLOGIJA
}

\author{
Radomir Jovičić ${ }^{1}$ \\ Olivera Popović2*, \\ Radica Prokić Cvetković2 \\ Dragan Cvetković ${ }^{3}$, \\ Nenad Milošević ${ }^{2}$
}

\author{
${ }^{1}$ Inovacioni centar, \\ Univerzitet u Beogradu, \\ Beograd, Srbija \\ ${ }^{2}$ Mašinski fakultet, \\ Univerzitet u Beogradu, \\ Beograd, Srbija \\ UUniverzitet Singidunum, \\ Beograd, Srbija
}

\begin{abstract}
Rezime:
Zavarivanje se široko primenjuje $\mathrm{u}$ industriji pri izradi različite opreme, mostova, kranova, transportnih sredstava i sl. Ono ima odlučujući uticaj na kvalitet, pouzdanost, vek i cenu izrade navedenih konstrukcija. Međutim, kvalitet izvedenih zavarenih spojeva je teško ili je često gotovo nemoguće utvrditi ispitivanjima na samim konstrukcijama. Zbog toga je potrebno praćenje toka izrade zavarenih konstrukcija od ugovaranja i projektovanja, preko kvalifikacije i sertifikacije osoblja i opreme, kvalifikacije procedura zavarivanja i kontrole tokom i nakon završene izrade konstrukcije. Zahtevi za kvalitet koje treba ispuniti u pojedinim fazama izrade konstrukcija definisani su u standardima serije EN ISO 3834.

Odstupanja izvedenog kvaliteta zavarenih spojeva od potrebnog najčešće nastaju u fazi zavarivanja. Do sada nije postojala mogućnost za kontinualno praćenje, beleženje i skladištenje podataka o parametrima zavarivanja. U radu je prikazan sistem zasnovan na informacionim tehnologijama, koji omogućava prikupljanje i beleženje podataka o parametrima zavarivanja, upotrebljenim materijalima i angažovanim zavarivačima, njihovo poređenje sa zadatim vrednostima i obustavljanje zavarivanja u slučajevima utvrđenih odstupanja. $\mathrm{Na}$ taj način se znatno poboljšava kvalitet i pouzdanost zavarenih konstrukcija.
\end{abstract}

Ključne reči:

zavarivanje, parametri, monitornig, informacione tehnologije.

\section{UVOD}

Danas se sa velikom izvesnošću može tvrditi da je sigurnost zavarenih konstrukcija tokom eksploatacije na visokom nivou. To je postignuto ugrađivanjem višegodišnjih iskustava u propise i standarde i razvojem materijala, tehnologija izrade i metoda kontrole tokom izrade i eksploatacije konstrukcija. Klasične metode projektovanja su zasnovane na proračunima koji uzimaju u obzir radne napone, karakteristike čvrstoće i plastičnosti materijala i koeficijent sigurnosti. Te metode ne uzimaju u obzir činjenicu da materijali sadrže greške koje su mogući začeci prslina i da tokom eksploatacije konstrukcija na materijalima mogu da nastanu različita oštećenja koja takođe mogu da budu mesta začetaka prslina. Tokom eksploatacije konstrukcija prsline, koje su nastale na greškama ili oštećenjima, mogu da izazovu lom tj. otkaz konstrukcije. Prema tome, otkaz konstrukcija mogu da izazovu samo prsline. Druge vrste grešaka
Odgovorno lice:

Olivera Popović

e-pošta:

opopovic@mas.bg.ac.rs 
u materijalima same po sebi ne mogu da budu uzrok otkaza, ali mogu da budu uzrok nastanka prslina [1].

Iskustva iz prakse pokazuju da su otkazi zavarenih konstrukcija najčešće izazvani nastankom i rastom prslina u zavarenim spojevima. Zavareni spojevi predstavljaju kritična mesta na zavarenim konstrukcijama zbog svoje hemijske i strukturne nehomogenosti, zbog promene geometrije zida na mestu zavarenog spoja, zbog zaostalih napona i zbog grešaka formiranja šava [2]. Verovatnoća otkaza u osnovnim materijalima, kao što su npr. nosači, oslonci, omotači i danca na opremi pod pritiskom, znatno je manja zato što oni imaju uglavnom ujednačene osobine u svim pravcima.

Da bi se povećala sigurnost zavarenih konstrukcija i smanjila opasnost od njihovog otkaza, usvojen je niz propisa i standarda $[3,4,5,6]$ koji definišu zahteve koje moraju da ispune materijali, osoblje, oprema, procedure za izradu i ispitivanja i sama preduzeća koja se bave izradom zavarenih konstrukcija. Najosetljivija operacija u procesu izrade zavarenih konstrukcija je samo zavarivanje. Najčešće se u toku operacije zavarivanja u zavarene spojeve ugrade greške koje kasnije mogu da dovedu do otkaza konstrukcija. Zbog toga propisi zahtevaju [3] odgovarajuće dokaze da su spojeve zavarili zavarivači sa odgovarajućim kvalifikacijama, koristeći propisane dodatne i pomoćne materijale i propisane parametre zavarivanja. Za najveći broj zavarenih spojeva takvi dokazi ne postoje. Takođe, u slučajevima da je bilo odstupanja od zadatih parametara zavarivanja, ona najčešće nisu registrovana.

Do sada nije postojao sistem koji bi mogao da obezbedi dokaze da su spojevi zavareni u skladu sa propisanim zahtevima i tako potvrdi da izvedeni spojevi zadovoljavaju propisani nivo kvaliteta. Razvoj informacionih tehnologija je omogućio registrovanje i kontinualno merenje bitnih podataka o zavarivanju kao što su npr. kvalifikacije zavarivača, kvaliteti dodatnih i pomoćnih materijala i parametari zavarivanja. To je omogućilo poređenje sakupljenih informacija sa odgovarajućim informacijama iz propisanih procedura zavarivanja WPS lista i, po potrebi, blagovremeno preduzimanje korektivnih aktivnosti. Na taj način je bitno poboljšan kvalitet i pouzdanost zavarenih konstrukcija.

\section{OTKAZI ZAVARENIH KONSTRUKCIJA}

I pored definisanih zahteva u pogledu kvaliteta zavarenih spojeva, kao i njihovog poštovanja tokom izrade, otkazi zavarenih konstrukcija tokom eksplotacije se dešavaju.
Na Slici 1 je prikazana havarija naftne platforme Alexander L. Kielland u vodama Norveške 1980. godine, koja je praćena i ljudskim žrtvama. Do havarije platforme je došlo usled loma jednog od njenih oslonaca. Lom oslonca je izazvala greška u zavarenom spoju.

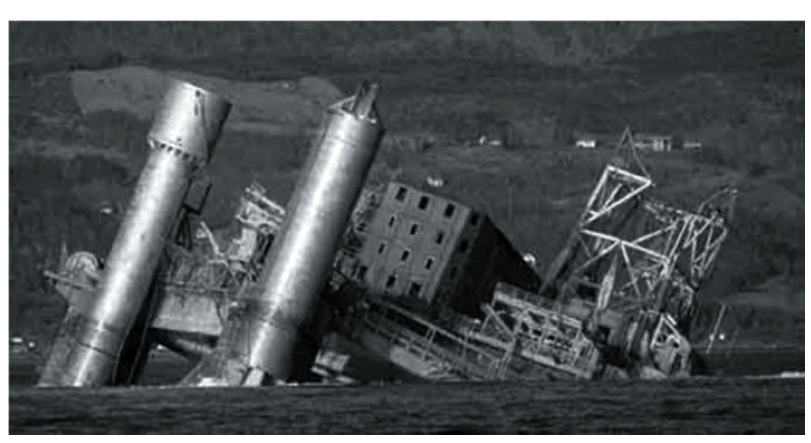

Slika 1. Lom naftne platforme

U jednoj od rafinerija nafte u SAD 1984. godine dogodila se eksplozija adsorberske kolone amina [7]. Kolona je namenjena za izdvajanje vodonik sulfida iz propana i butana. Do eksplozije je došlo usled paljenja mešavine propana i butana koja je iscurila kroz pukotinu u zidu kolone. Usled eksplozije gornji deo kolone dužine $14 \mathrm{~m}$ je odleteo skoro $1 \mathrm{~km}$ i tom prilikom je poginulo sedamnaest radnika rafinerije.

Naknadna ispitivanja su pokazala da je pukotina, koja je bila uzrok eksplozije, nastala u spoju koji je zavaren pri zameni dela omotača kolone. Okolina zavarenog spoja, tj. njegova zona uticaja toplote, imala je martenzitnu strukturu koja nije odgovarajuća za uslove eksplotacije kolone i koja je nastala zbog nepoštovanja propisane procedure zavarivanja. Ova greška nije registrovana tokom zamene dela omotača kolone, niti pre njenog puštanja u rad.

U Rafineriji nafte u Srbiji, 2013. godine je pri utakanju došlo do loma i do propuštanja zavarenog spoja na autocisterni namenjenoj za transport sirove nafte i bitumena. Ispitivanja su pokazala da je do loma i propuštanja cisterne došlo u donjem delu jednog od kružnih spojeva na omotaču cisterne. Slika 2a je snimljena sa spoljne cisterne i pokazuje pukotinu, dužine oko $1,5 \mathrm{~m}$, koja prolazi kroz celu debljinu zida cisterne. Slika $2 b$ je snimljena sa unutrašnje strane cisterne. Prava tamna linija na slici predstavlja grešku - neprovaren koren, otkrivenu u spoju u kome je došlo do loma i do procurivanja. Greška je napravljena pri proizvodnji cisterne. Cisterna je korišćena više godina sa ovom greškom u spoju. Greška je nastala zbog nepoštovanja propisanih parametara zavarivanja. Lom je izazvao samo materijalnu štetu. 

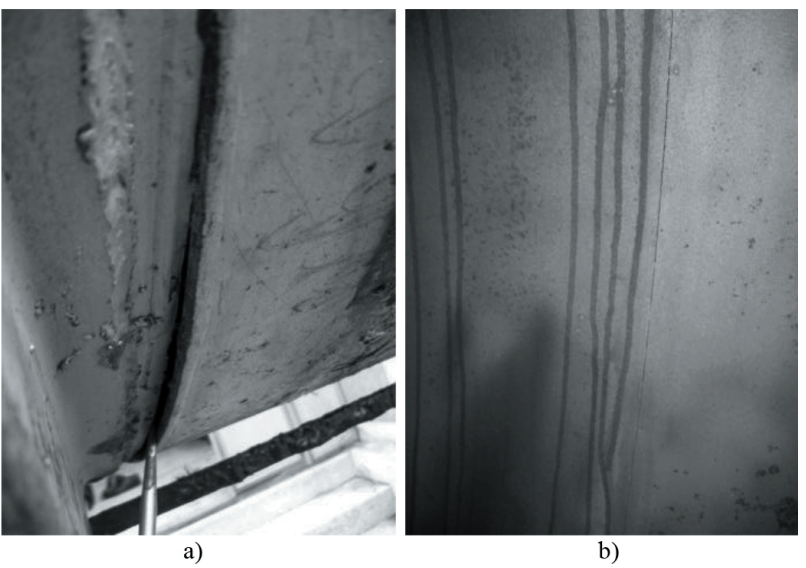

b)

Slika 2. a) pukotina u zavarenom spoju cisterne kroz koju je došlo do izlivanja,

b) neprovaren koren u spoju u kome je došlo do loma

\section{OBEZBEĐENJE KVALITETA ZAVARENIH KONSTRUKCIJA}

Standardi koji se bave obezbeđenjem kvaliteta [8] svrstavaju zavarivanje topljenjem u grupu specijalnih operacija zato što se izvedeni kvalitet zavarenih spojeva ne može u potpunosti utvrditi ispitivanjima na konstrukcijama. Da bi se dobili dovoljno kvalitetni i pouzdani zavareni spojevi potrebna je kontrola celog procesa izrade zavarene konstrukcije od faze projektovanja, preko izbora materijala, do proizvodnje i završnih ispitivanja. Standardi serije SRPS EN ISO 3834 definišu zahteve koje treba ispuniti da bi se obezbedio potreban kvalitet zavarenih konstrukcija. Ovi standardi obuhvataju preispitivanje zahteva naručioca konstrukcije, preispitivanje sposobnosti proizvođača za izradu konstrukcije, preispitivanje kompetentnosti osoblja za koordinaciju u zavarivanju i kompetentnosti zavarivača i preispitivanje pogodnosti, ispravnosti i kapaciteta raspoložive opreme. Takođe, ovi standardi nalažu i korišćenje kvalifikovanih procedura za zavarivanje - WPS lista, korišćenje osnovnih, dodatnih i pomoćnih materijala dokazanog kvaliteta, obučeno i sertifikovano osoblje za kontrolu i ispitivanja, upotrebu proverene i baždarene opreme za kontrolu i ispitivanja i posedovanje i primenu odgovarajućih procedura za postupak sa dokumentacijom.

Međutim, i potpuna i dosledna primena navedenih standarda ne sprečava uvek pojavu grešaka u zavarenim spojevima. Tokom zavarivanja, čak i u slučaju neprekidnog nadzora nad radom svakog zavarivača, nije moguće registrovati svako odstupanje od zadatih parametara. Naime, tokom zavarivanja parametri kao što su dužina slobodnog kraja žice kod MIG/MAG postupka, jačina struje, napon i brzina zavarivanja se neprekidno menjaju. Pri tim promenama je moguće da navedeni parametri izađu iz oblasti zadatih vrednosti, što može biti praćeno nastankom grešaka u zavarenim spojevima. U slučajevima grubljeg narušavanja tehnološke discipline može doći i do zamene dodatnog materijala, zaštitnog gasa ili WPS liste, ili je moguće da spojeve zavaruju zavarivači koji nemaju odgovarajuće kvalifikacije.

Dosadašnji način kontrole operacije zavarivanja je bio povremen, čak i kada su u pitanju bile najodgovornije konstrukcije, kao što su npr. objekti procesne industrije, energetike i naftne platforme. Takav način kontrole nije obezbeđivao kontinuirani uvid u promene parametara zavarivanja. Zbog toga se dešavalo da se u zavarenim spojevima pojave greške koje su kasnije, tokom eksplotacije, dovodile do katastrofalnih lomova konstrukcija. Da bi se ovakvi slučajevi izbegli i da bi se obezbedio potrebni, ujednačeni i ponovljivi nivo kvaliteta zavarenih spojeva, potreban je sistem stalnog praćenja parametara zavarivanja tj. sistem monitoringa. Standardi [3] predviđaju i da zavarivačke radove moraju da prate odgovarajući dokumenti koji omogućavaju uvid u poštovanje predviđenih procedura i uvid u eventualna odstupanja od tih procedura, zbog čega sistem monitoringa mora da obezbedi i mogućnost izrade i štampanja odgovarajućih dokumenata.

\section{MONITORING OPERACIJE ZAVARIVANJA}

Da bi se dobili zavareni spojevi potrebnog, ujednačenog i ponovljivog kvaliteta, standardima je propisano da se pre početka zavarivanja izrađuju WPS liste [9]. One predstavljaju uputstva koja sadrže sve potrebne podatke za zavarivanje određenog tipa spoja. Do ovih podataka se dolazi prethodnim zavarivanjem i ispitivanjem više uzoraka. Dosledno sprovođenje usvojenih WPS lista garantuje da se u sledećim spojevima istog tipa neće pojaviti neprihvatljive greške. Osim podataka o kvalitetu i dimenzijama osnovnog i dodatnog materijala, WPS liste sadrže i podatke o tipu spoja, načinu pripreme žleba, položaju zavarivanja, postupku zavarivanja, broju i rasporedu zavara, vrsti i jačini struje, naponu i brzini zavarivanja, količini unete energije, vrednosti temperature predgrevanja i međuprolazne temperature i podatke o potrebnoj kvalifikaciji zavarivača.

Stabilan i siguran kvalitet zavarenih spojeva je moguće obezbediti samo ako postoji sigurnost da su parametri iz usvojenih WPS lista uvek tačno reprodukovani. Kontinualno praćenje i poređenje parametara zavarivanja sa podacima iz WPS lista obezbeđuje sistem za monitoring zavarivanja zasnovan na informacionim tehnologijama [10]. 
Sistem za monitoring zavarivanja funkcioniše na sledeći način: pre početka zavarivanja, zavarivač se, pomoću ručnog skenera, priključi na sistem, Slika 3. Skeniranjem bar-koda sa identifikacione kartice učitavaju se lični podaci i kvalifikacija zavarivača, Slika 3a. Zatim se skenira bar-kod WPS liste spoja koji treba da bude zavaren, Slika 3b. Sistem poredi kvalifikaciju zavarivača sa potrebnom kvalifikacijom prema WPS listi. To garantuje da kvalifikacija zavarivača odgovara WPS listi spoja koji treba da bude zavaren i da je kvalifikacija u okviru važećeg vremenskog perioda. Izabrani dodatni materijal i zaštitni gas se takođe skeniraju, porede i potvrđuju, Slika 3c. Na ekranu skenera se pomoću informacija koje su praćene jarkim bojama, Slike 3c i 3d, potvrđuje ili se negira saobraznost unetih podataka sa WPS listom $i$ time se garantuje da je zavarivač informisan i da u slučaju potrebe treba da preduzme korektivne mere da bi se izbeglo odstupanje od potrebnog kvaliteta spoja.
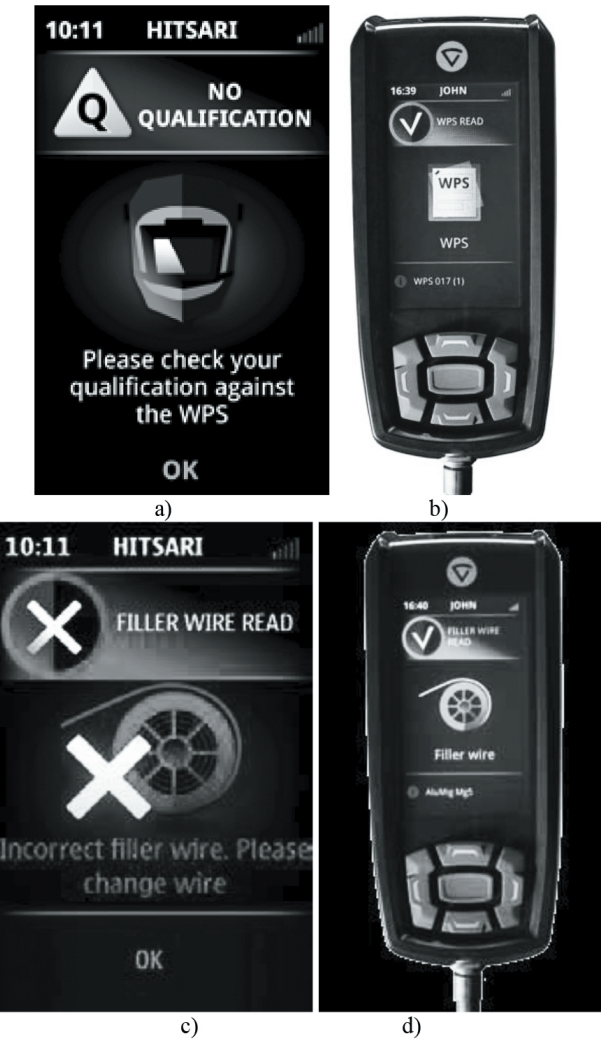

c)

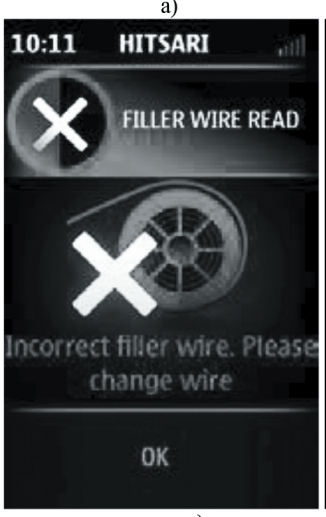

Slika 3. a) unos podataka za zavarivača, b) unos WPS liste, c) dodatni materijal nije odgovarajući za unetu WPS listu, d) upotrebljen odgovarajući dodatni materijal za unetu WPS listu

Učitani podaci se trajno snimaju. Kompanije koje rade na više lokacija mogu da organizuju daljinsko memorisanje i kontrolu unetih podataka pomoću inovativnog sistema razmene informacija na bazi „cloud” podrške, Slika 4.

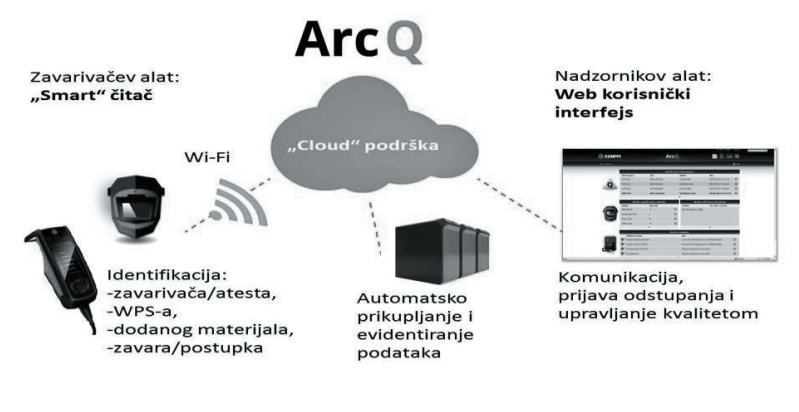

Slika 4. Način rada informacionog sistema za monitoring operacije zavarivanja

Zahvaljujući mogućnosti ulaza u sistem i uvida u podatke sa bilo koje lokacije moguće je održavanje kvaliteta i upravljanje proizvodnjom sa jednog mesta. To daje mogućnost istovremene kontrole rada većeg broja zavarivača preko veb korisničkog interfejsa, Slike 5 i 6 . Korisnički interfejs omogućava i da se osoba koja nadzire zavarivanje umeša ako su potrebne korektivne mere, a one nisu preduzete na zavarivačkom radnom mestu.

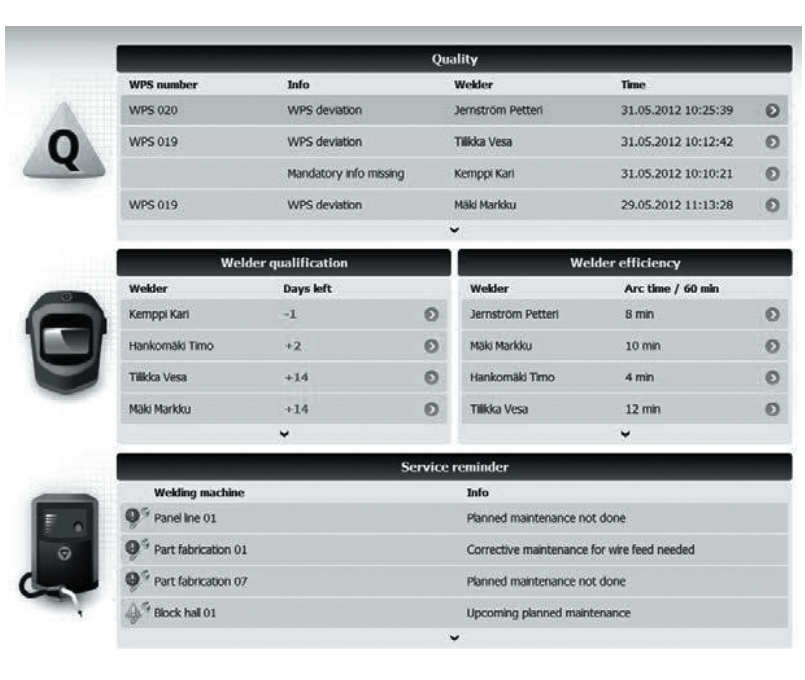

Slika 5. Izgled korisničkog interfejsa, monitoring operacije zavarivanja

Slika 5 pokazuje da sistem za monitoring omogućava da se uoči da je tokom zavarivanja došlo do odstupanja od zadatih parametara datih u WPS listi i da se uoče zavarivači koji su napravili odstupanja. Sistem daje uvid u rok važnosti kvalifikacija zavarivača, preostali period važenja ovih kvalifikacija i u efektivno radno vreme zavarivača. Takođe, mogu se videti podaci o ispravnosti uređaja za zavarivanje, podaci o uređajima koji na servisu, razlozi za servisiranje i plan tekućeg održavanja uređaja. 
Slika 6 pokazuje da sistem za monitoring omogućava i detaljno praćenje rada svakog zavarivača pojedinačno. Sa slike se vidi da su zadate maksimalne i minimalne vrednosti jačine struje i napona i da se može očitati i vreme trajanja zavarivanja. Slika pokazuje i da li je zavarivač tokom rada izlazio iz zadatih opsega struje i napona i time stvorio mogućnost da se u spoju pojave nedozvoljene greške. Na osnovu ovih parametara i trajanja zavarivanja može se izračunati i količina unete energije koja je vrlo važan parametar, naročito kod zavarivanja konstrukcija izloženih visokim naprezanjima. Slika pokazuje da se mogu beležiti i greške koje je zavarivač napravio, razlozi nastanka grešaka kao i preduzete korektivne mere.

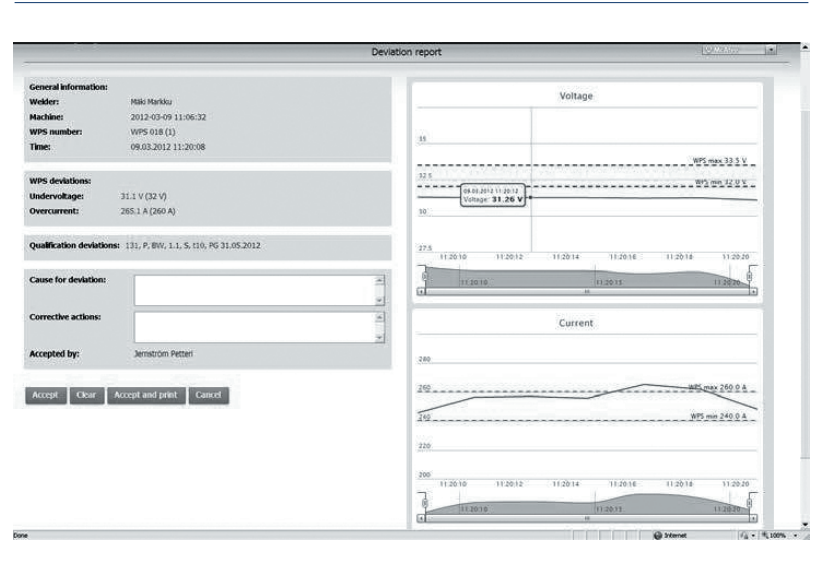

Slika 6. Izgled korisničkog interfejsa, monitoring rada jednog od zavarivača

\section{ZAKLJUČAK}

Greške u zavarenim spojevima se javljaju zbog odstupanja parametara zavarivanja od zadatih vrednosti. Danas se primenjuje sistem praćenja parametara zavarivanja koji se zasniva na povremenoj kontroli. Zbog toga se neka odstupanja parametara od zadatih vrednosti ne registruju, pa se greške koje su posledica ovih odstupanja otkriju tek ispitivanjem spoja nakon zavarivanja ili se uopšte ne otkriju.

Sistem koji omogućava kontinuirano praćenje parametara zavarivanja, tj. monitoring zavarivanja, kontinualno snima parametre i omogućava da se registruju odstupanja od zadatih vrednosti. To znatno smanjuje verovatnoću pojave grešaka u zavarenim spojevima.

Osim toga, ovaj sistem prikazuje podatke o efikasnosti sa uređaja za zavarivanje i cele proizvodne linije, olakšava prepoznavanje „uskih grla” u proizvodnji, garantuje da zavarivanje izvode zavarivači sa potrebnim kvalifikacijama, omogućava daljinsku kontrolu i korektivne mere, automatski sakuplja podatke, snižava troškove zbog popravki loših zavara, daje informacije o trajanju zavarivanja i zastojima u zavarivanju, racionalizuje upravljanje zavarivačkom opremom i njenim održavanjem i daje podršku zavarivačima i specijalistima za zavarivanje.

\section{ZAHVALNOST}

Ovaj rad je proistekao iz rezultata istraživanja na projektu Ministarstva prosvete, nauke i tehnološkog razvoja Republike Srbije TR 35024.

\section{LITERATURA}

[1] R. Jovičić: Procena sigurnosti zavarenih posuda pod pritiskom ispitivanjem u toku eksploatacije, Magistarski rad, Tehnološko metalurški fakultet u Beogradu, Beograd, 1998.

[2] R. Jovičić, S. Petronić, O. Erić Cekić: Zavareni spoj kritično mesto na opremi pod pritiskom, 29. Međunarodni kongres o procesnoj industriji "Procesing 2016.", Beograd, Republika Srbija, 02-03. jun 2016.

[3] Standard SRPS EN ISO $3834-1$ - 5/2008, Zahtevi kvaliteta kod zavarivanja topljenjem metalnih materijala

[4] Standard SRPS EN ISO 15614 - 1/2017; Specifikacija i kvalifikacija tehnologije zavarivanja metalnih materijala - Kvalifikacija tehnologije zavarivanja - Deo 1: Elektrolučno i gasno zavarivanje čelika i elektrolučno zavarivanje nikla i legura nikla

[5] Standard SRPS EN ISO 9712/2013; Ispitivanje bez razaranja - Kvalifikacija i sertifikacija osoblja za IBR

[6] Standard SRPS EN ISO 9606/2015; Kvalifikaciono ispitivanje zavarivača - Zavarivanje topljenjem

[7] S. Sedmak: Eksploatacijske prsline u zavarenim spojevima posuda pod pritiskom, monografija Eksploatacijske prsline u posudama pod pritiskom i rezervoarima, TMF - Goša, Beograd, 1994.

[8] Standard SRPS ISO 9000/2015; Sistem menadžmenta kvalitetom

[9] Standard SRPS EN ISO 15609-1/, Specifikacija i kvalifikacija tehnologije zavarivanja metalnih materijala - Specifikacija tehnologije zavarivanja - Deo 1: Elektrolučno zavarivanje, 2008.

[10] Kemppi Arc System 2.0, New Module ArcQuality - самая функциональная система управления качеством сварки, Kemppi ProNews 2012, Kemppi Oy, Finska, 2012., p.p. 8 -10. 